\title{
LOW COST BLDC DRIVE USING SINGLE CURRENT SENSOR
}

\section{GOPALAKRISHNAN ${ }^{1} \&$.V. GOPALAKRISHNAN ${ }^{2}$}

${ }^{I}$ Electrical and Electronics Engineering, Sri Ramakrishna Polytechnic College, Coimbatore, Tamil Nadu, India

${ }^{2}$ Electrical and Electronics Engineering, Alagappa Chettiar College of Engineering, Karaikudi, Tamil Nadu, India

This paper provides a technique to minimize torque ripple in BLDC motor by using single current sensor. There are number of techniques avail to minimize torque ripple. This paper proposes hysteresis current controller. By using this controller torque ripple is greatly reduced in various speed and loading conditions. Simulation is carried out using MATLAB / SIMULINK. The results show that the performance of BLDC motor is quite satisfactory.

KEYWORDS: Brushless DC Motor, Trapezoidal Type Machine, PM Synchronous Motor \& Torque Ripple Minimization
\end{abstract}

Received: Jul 20, 2017; Accepted: Aug 05, 2017; Published: Aug 11, 2017; Paper Id.: IJEEERAUG201710

\section{INTRODUCTION}

Brushless DC motors BLDC are more popular in recent years due to its high efficiency, high power density, high torque to inertia ratio for a given machine size and simple control characteristics. The application range in various fields like automobile and robotics, in BLDC motor $120^{\circ}$ mode of rectangular wave voltage commutation is used, due to motor armature resistance and inductance the current waveform is not exact wave during commutation. This causes undesirable torque ripple. Theoretical analysis for torque ripple is available in [13].This torque ripple leads to visible vibrations, acoustic noise and error in sensor less motor drives. The torque ripple varies with speed and may reach $50 \%$ of the average torque.

Torque ripple exists due to cogging, imperfection of back emf waveforms, supply current ripple from PWM inverters and phase current commutation. Many technologies have developed for minimizing torque ripple. The cogging torque can be minimized by skewing the stator teeth or by changing the magnet's dimension and position [3].An alternative approach for minimizing torque ripple, Current control is adopted in many ways because, current control is simple and effective method. For current control, PWM or hysteresis controls are adopted. In [4-11] phase current control is implemented during phase current commutation in a BLDC motor using phase current sensors.

This paper proposes a simple current control method to restrain the commutation torque ripple in the various speed ranges with a single current sensor. This control system has very simple configuration and reliable performance. Complex control strategies for BLDC motor are sensitive to variation in parameters, magnetic saturation and also makes less reliable for entire system. For domestic or simple applications where the operating parameters are not frequently varies, then the control strategies required for BLDC motor should also be simple. This simple control system will be available at low cost and uses simple structure. 


\section{MATHEMATICAL MODEL}

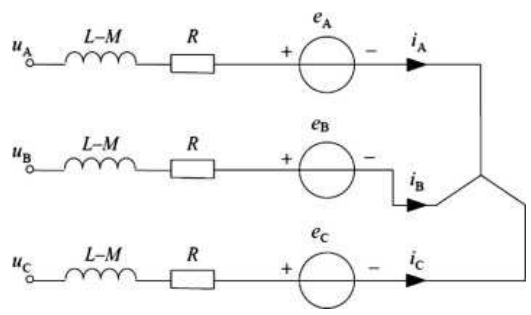

Figure 1

In ideal condition BLDC motor produces a traphizoidal back emf and excited with rectangular current wave form, due to this reason torque is uniform and ripple free. The ideal back emf and current wave form is shown in the figure 2 , assume, the per phase resistance and inductance are equal. The self and mutual inductance are constant irrespective of rotor position. The rotor induced current are neglected and the damper winding are also not present.

The Voltage Equation of the BLDC Motor can be expressed as

$$
\begin{aligned}
& v_{1}=R_{1}+L \frac{d i_{1}}{d t}+e_{1} \\
& v_{2}=R_{2}+L \frac{d i_{2}}{d t}+e_{2} \\
& v_{3}=R_{3}+L \frac{d i_{3}}{d t}+e_{3}
\end{aligned}
$$

In matrix form

$$
\left[\begin{array}{l}
v_{1} \\
v_{2} \\
v_{3}
\end{array}\right]=\left[\begin{array}{lll}
R & 0 & 0 \\
0 & R & 0 \\
0 & 0 & R
\end{array}\right]\left[\begin{array}{l}
i_{1} \\
i_{2} \\
i_{3}
\end{array}\right]+\left[\begin{array}{ccc}
l-M & 0 & 0 \\
0 & l-M & 0 \\
0 & 0 & l-M
\end{array}\right] \frac{d}{d_{t}}\left[\begin{array}{l}
i_{1} \\
i_{2} \\
i_{3}
\end{array}\right]+\left[\begin{array}{l}
e_{1} \\
e_{2} \\
e_{3}
\end{array}\right]
$$

Where, $R$ is the phase Resistance and $i_{1}, i_{2}, i_{3}$ are the phase current, $e_{1}, e_{2}, e_{3}$ are the back emf, $l$ and $M$ are the self and mutual inductance, of the individual coil.

Due to the interaction between the stator current and magnetic field from rotor magnets, the electromagnetic torque has been developed.

$$
T_{e}=\frac{e_{1} i_{1}+e_{2} i_{2}+e_{3} i_{3}}{\omega_{m}}
$$

Where, $\omega_{m}$ is the angular speed of the machine.

For $120^{\circ}$ mode six step motor controls, two phases are connected in series at each step. The instantaneous power is given by

$$
p_{i=} \omega_{m} T_{e}=2 E I
$$

Where $\mathrm{I}=$ current amplitude and $\mathrm{E}$ is the induced back emf.

Output torque can be expressed as

$T_{e}=2 K \Phi I=2 k_{t} I$

Where $k_{t}$ is motor torque constent. 


\section{Analysis of Torque Ripple}

It is proposed in [10] that a single dc current sensor and a current deadbeat control scheme should be used to keep incoming and outgoing phase currents changing at the same rate during commutation. The study [10] presents a comprehensive analysis of the commutation torque ripple suppression method in brushless dc motor drives with only a single current sensor. BLDC motor is driven through 3 phase full bridge six step voltage source inverter. Each phase is energized for the interval of $120^{\circ}$ electrical degree according to the rotor position. For providing current path in each step, one phase is energized as positive and another is energized as negative.

For analysis of commutation mode, the commutation of the current through two phases will be considered. One phase will be switched off, the second phase will replace the switched off phase and the third phase will be remained conduction called non-commutated phase.

Consider the commutation from phase 1 to phase2. The current transfer happens during the commutation interval in this analysis, current transfers from phase1(+) to phase2(+). Phase3 (-) will be in the same condition. Phase1 is called the outgoing phase, phase 2 is called incoming phase and phase 3 is called conducting phase.

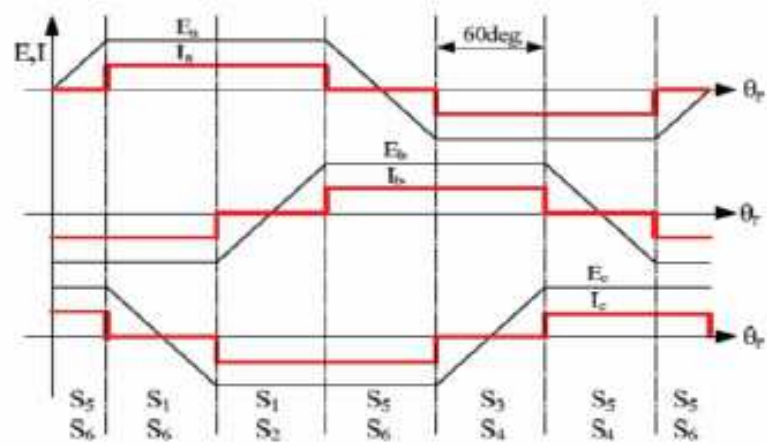

Figure 2: Ideal Back Emf and Current Wave

For ripple free uniform torque, the current in BLDC motor with traphizoidal back emf is rectangle in shape. Figure 2 shows the ideal phase current wave forms. In this, the incoming current $i_{2}$ takes the finite time to reach its maximum value, also the outgoing current $i_{1}$ takes a finite time to reach zero.

Figure 3 shows the six step inverter, at each 60 electrical degree there will be 2 switches conducting at the same time. One from positive group i.e. upper arm and another from negative group i.e. lower arm. When phase1 and phase3 conducting, the upper arm switch S1 and lower arm switch S4 will be in ON position. During commutation period switch S1 turned OFF, the current will be decayed through the freewheeling diode D6 and the switch S4. This will take a short period which will occur at each step. In the next sequence switch S3 and switch S4 will be in ON position. Now phase2 and phase 3 are conducting. 

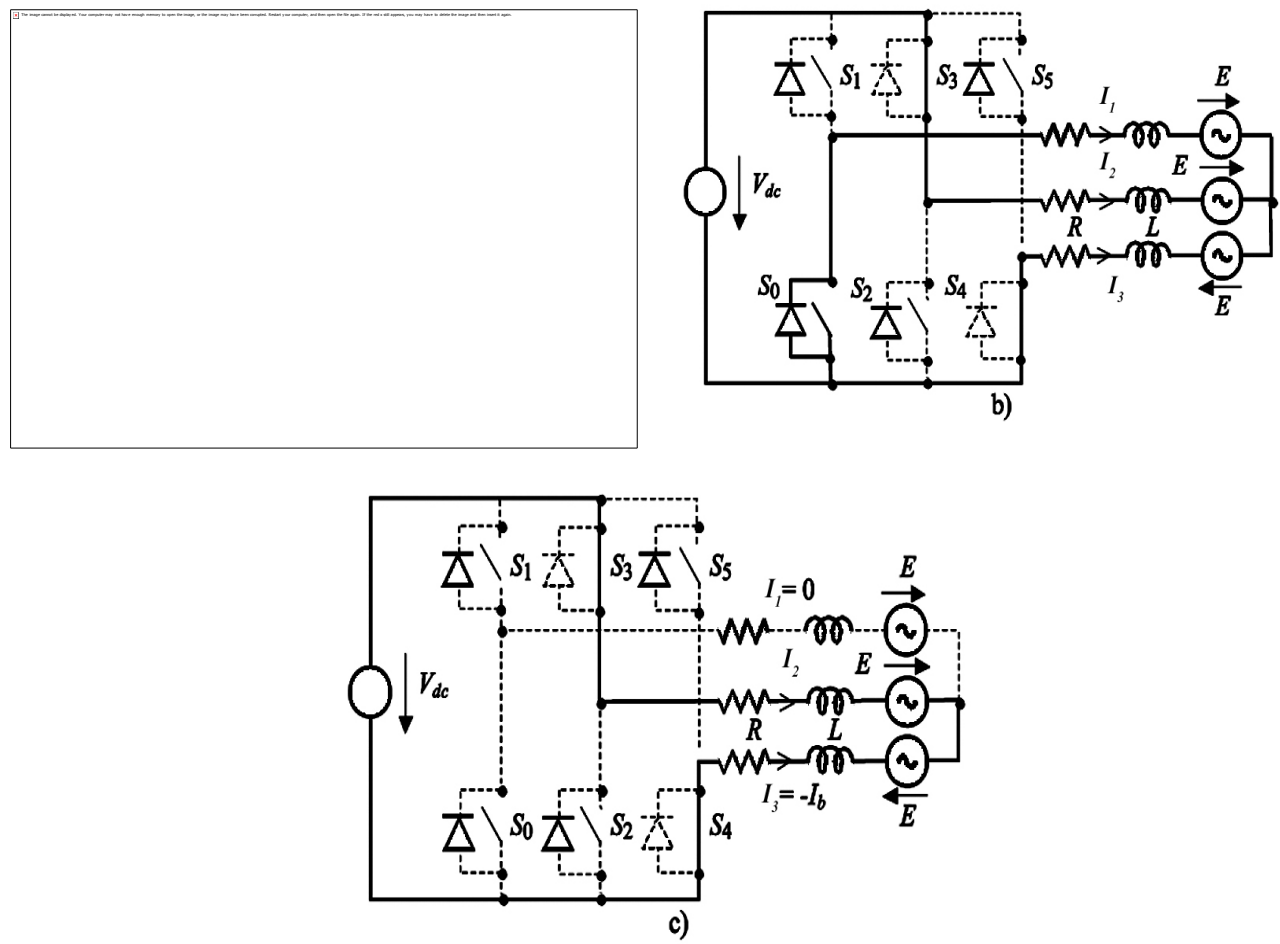

Figure 3: Commutation of Phase Current from Phase1 to Phase2 (A) Phase1 Conducts, (B) Commutation Between Phase1, 2 (C) Phase2 Conducts

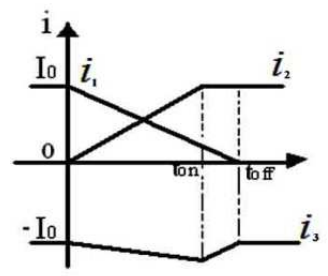

I

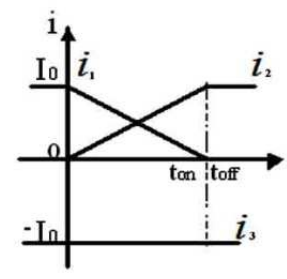

II

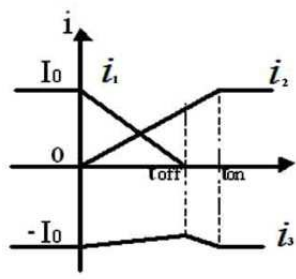

III

Figure 4: Waveforms of Phase Currents during Commutation in Different Cases

Slop of the curve is can be calculated from

$$
\begin{aligned}
& L \frac{d i_{1}}{d t}+R i_{1}+E_{1}-\left(L \frac{d i_{3}}{d t}+R i_{3}+E_{3}\right)=0 \\
& L \frac{d i_{2}}{d t}+R i_{2}+E-\left(L \frac{d i_{3}}{d t}+R i_{3}+E\right)=V_{d c}
\end{aligned}
$$

In practical situation, due to the phase resistance and inductance, the rate of rise of incoming current is not equal to the rate of drop of outgoing current. This mismatch produces torque ripple. Consider figure 4 (a) the current in the outgoing phase would reach zero before the current in incoming phase reach maximum value.

$$
\frac{d_{i 1}}{d_{t}}>\frac{d_{i 2}}{d_{t}}
$$

Therefore the non commutated phase 3 current will rise up slightly during commutation period.

In figure 4(b) phase 1 rate of drop of outgoing current $i_{1}$ is slower than the phase 2 rate of rise of the incoming 
current $\mathrm{i}_{2}$.

$$
\frac{d_{i 1}}{d_{t}}<\frac{d_{i 2}}{d_{t}}
$$

Due to this mismatch a small dip appear in the phase3 during commutation period. Therefore overall torque produced in the motor has ripples.

In figure $4(c)$ phase 1 rate of drop of outgoing current $i_{1}$ is equal to phase 2 rate of the rise of incoming current $i_{2}$.

$$
\frac{d_{i 1}}{d_{t}}=\frac{d_{i 2}}{d_{t}}
$$

In this condition no dip appears in the phase 3 during commutation period. This leads to ripple free torque in output.

\section{HYSTERESIS CURRENT CONTROLLER}

Among the various PWM techniques, the hysteresis band current control is reliable and easy to implement. Also it has very fast response and effective current loop. The method does not need any knowledge of motor and load parameters. However, the current control with a fixed hysteresis band has the certain limitations that the PWM frequency varies within a band because peak-to-peak current ripple is required to be controlled at all points of the fundamental frequency wave.

The PWM current controller acts once a cycle, controlling the duty cycle of the chopper. The chopper is a variable voltage source with average current control. Instantaneous current control is not exercised in the PWM current controller.

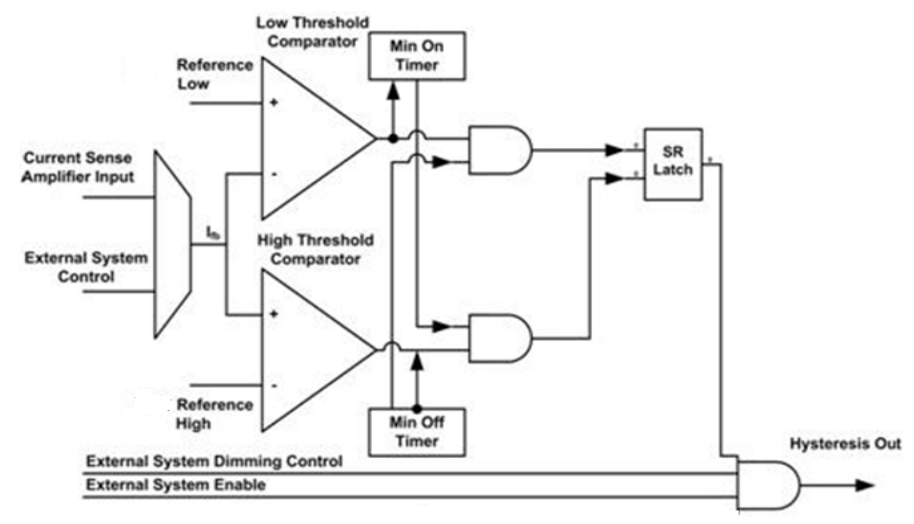

Figure 5: Block Diagram of Hysteresis Current Controller

In between two consecutive switching, the current can exceed the maximum limit; if the PWM controller is sampled and held once a switching cycle, then the current is controlled on an average but not on an instantaneous basis. The hysteresis controller overcomes such a drawback by converting a voltage source into a fast acting current source. The current is controlled within a narrow band of excursion from its desired value in the hysteresis controller. The hysteresis window determines the allowable or preset deviation of current Figure 5 shows the block diagram of hysteresis current controller which is generate the gating signals for inverter switches.

The DC link current $i_{d}$ is measured and compared with preset value of reference current. The error is fed to a comparator with a preset hysteresis band. Switching of the devices (S1 off) occurs when the line current exceeds a preset value corresponding to the desired line current $i_{d}$. The reverse switches ( $\mathrm{S} 1$ on) occur when the line current reaches less 
than desired $i_{d}$.

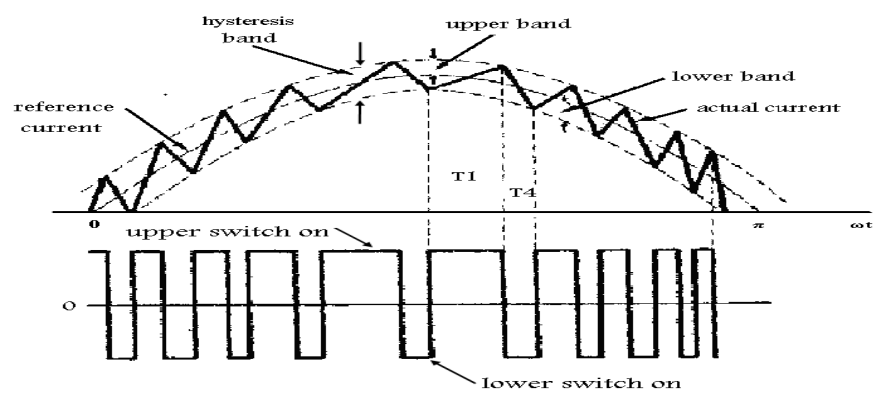

Figure 6: Hysteresis Controller Output Waveform

Hysteresis current control is simple to implement and produces a very good quality of wave form. The switching pattern gives as

$$
\begin{aligned}
& \text { If } \Delta i_{d}>H \mathrm{~S} 1 \text { is off } \\
& \Delta i_{d}<H \quad \mathrm{~S} 1 \text { is on }
\end{aligned}
$$

\section{PROPOSED TECHNIQUE}

Mainly Torque ripples occur during commutation period only. In voltage source inverter, commutation between the three phases is occurred six times per electrical revolution. As a result, output current ripples are generated during commutation period, this leads to torque ripples. This output current ripple reflects ripples in input DC link. A current sensor is placed in the DC link to measure the input current value. Measured current is feed to hysteresis current controller. Whenever the input current ripple above the pre set value in the hysteresis current controller, corresponding outgoing switch is driven by switching pulse which was generated by hysteresis controller instead of switch off. Pulse generated by the hysteresis controller is extended up to the incoming current reaches $80 \%$ of its maximum value.

By using this technique, in un commutated phase current ripple is minimized, therefore torque ripple is minimized in motor output.

\section{SIMULATION RESULTS}

To verify the effectiveness of the proposed technique, simulation using MATLAB Simulink is carried out. Motor parameters are 4 pole, $24 \mathrm{~V}, 200 \mathrm{~W}$ and $1500 \mathrm{rpm}$. Simulation results of the phase currents, dc-link current and torque ripple are illustrated in the speed range of $1200 \mathrm{rpm}$.

For easy comparison, switching algorithm is implemented for two phases only. Therefore in the six step sequence, four are controlled by new algorithm and two are uncontrolled. Proposed algorithm effectively neutralizes the mismatched phase current during commutation period and minimizes the commutation torque ripple over entire speed range..By using this technique torque ripple is minimized up to 65 percentages. The inverter's line current is shown in figure 8 . The stator phase current wave form is shown in figure 9. The rotor toque is shown in figure 10. 


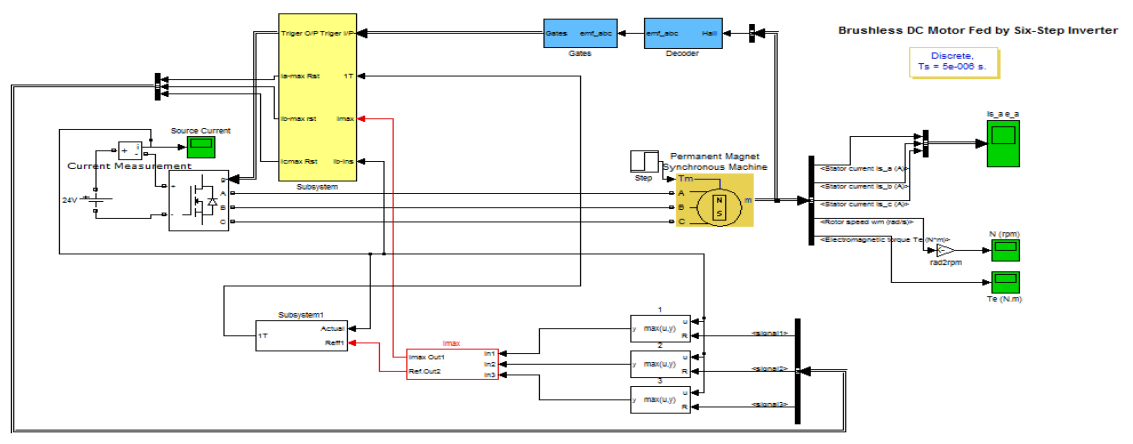

Figure 7: MATLAB Simulation of Conventional Six Switch Fed Single Current Sensor BLDC Motor Drive

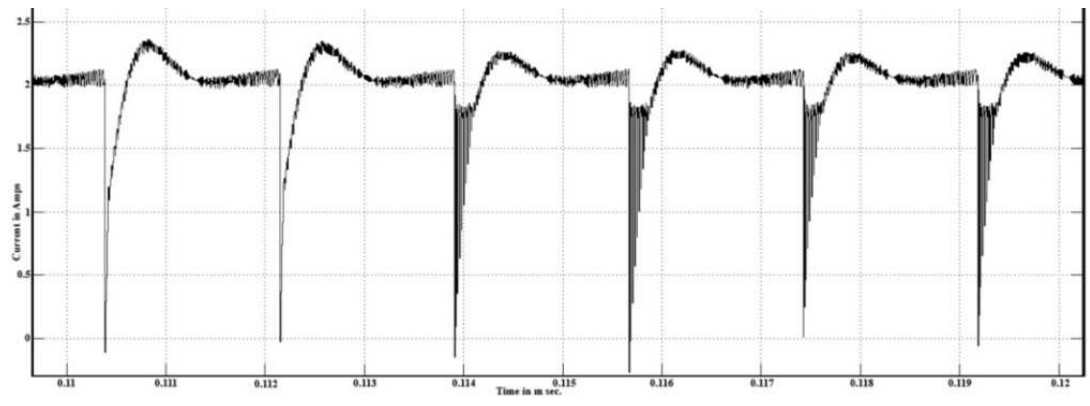

Figure 8: Line Current

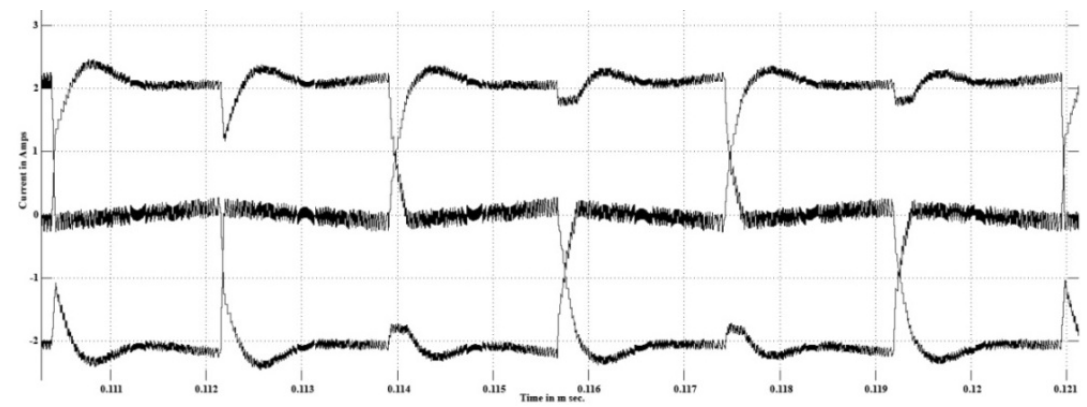

Figure 9: Phase Current

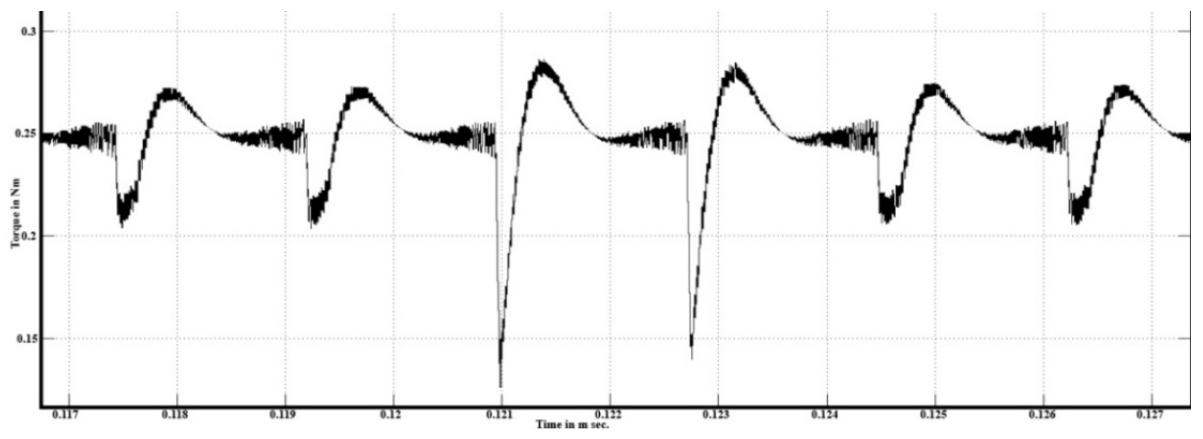

Figure 10: Torque Ripple

\section{MOTOR PARAMETERS}

Voltage $24 \mathrm{~V}$

Power 200W 
Phase Resistance

Phase Inductance

Torque constant

Back EMF constant
$0.19 \mathrm{Ohm}$

$0.517 \mathrm{mH}$

$0.11 \mathrm{Nm} / \mathrm{A}$

7.0 $/ \mathrm{Krpm}$

\section{CONCLUSIONS}

This paper has presented an analytical study of torque ripple and DC link current sensing using single current sensor. In this paper torque ripples of BLDC motor drive with hysteresis current controller loop is carried out and it is compared with, without hysteresis current controller fed BLDC drive. Simulation results shows that current ripple and torque ripple are minimized which enhances the drive performance. The results show that the dynamic performance of the motor is quite satisfactory for various speed conditions.

\section{REFERENCES}

1. M. Lajoie-Mazene, R. Carlson, and J.C Fagundes, "Analysis of torque ripple due to phase commutation in brushless DC machines," in IEEE Ind. Applicat. Soc. Annu. Meeting, Seattle, WA, 1990, pp.287-292.

2. A. H. Niassar, A. Vahedi, and H. Moghbelli, "Analysis and control of commutation torque ripple in four-switch three-phase brushless dc motor drive," in Proc. IEEE Ind. Technol. Conf., 2006, pp. 239-246.

3. P. Pillay and R. Krishnan, "Modeling, Simulation, and Analysis of Permanent Magnet Motor Drives. II. The brushless motor drive. Industry Applications, IEEE Transactions on 25(1989). pp. 272-279.

4. J. Cros et al., "A novel current control strategy in trapezoidal EMF actuators to minimize torque ripple due to phase commutation,” in EPE Eur. Conf. Power Electron., Applicat. (EPE), Brighton, U.K., vol.4, 1993, pp.266-271.

5. T. M. Jahns and W. L. Soong, "Pulsating torque minimization techniques for Permanent magnet AC motor drives-a review", IEEE Trans. on Industrial Electronics, vol. 43, 321-330, 1996.

6. T.S. Kim, S.C. Ahn, “A new current control algorithm for torque ripple reduction of BLDC motors," Proc.27 th Annu. Conf. IEEE Ind. Electron. Soc., Nov.29-Dec.2,2001, vol.2, pp.1521-1526.

7. J.W. Dixon and L. A. Leal. "current control strategy for brushless DC motors based on common", in IEEE Trans. on Power Electronics, vol. 17, 232-240, 2002

8. G. J. Su and J. W. Mckeever, "Low-cost sensorless control of brushless DC motors with improved speed range," IEEE Trans. Power Electron., vol. 19, no. 2, pp. 296-302, Mar. 2004.

9. F. P. Xu, T. C. Li, and P. H. Tang, "A low cost drive strategy for BLDC motor with low torque ripples," in Proc. IEEE Ind. Electron. Appl., Conf., 2008, pp. 2409-2502.

10. Song J.-H., and Choy I., "Commutation torque ripple reduction in brushless dc motor drives using a single dc current sensor," IEEE Trans. Power Electron., Mar(2004) Vol.19, No.2,312-319.

11. S. Ziaeinejad, Y. Sangsefidi, and A. Shoulaie, "Analysis of Commutation Torque Ripple of BLDC Motors and a Simple Method for Its Journal of Control and Systems Engineering 2016, Vol. 4 Iss. 1, PP. 20-31 - 31 - DOI: 10.18005/JCSE0401003 Reduction," International Conference on Electrical Engineering and Informatics, pp. 1-6, 17-19 July, Bandung, Indonesia, 2011 